\title{
After Years of Decline, Private Health Insurance Rates Among Children Grew in 2014
}

Michael J. Staley

$\mathrm{R}$ ates of private health insurance coverage for children increased between 2013 and 2014 for the first time since 2008, the first year in which the American Community Survey collected data on health insurance (see Figure 1). The rise corresponds with the implementation of the individual mandate under the Affordable Care Act (ACA), the opening of state and federal insurance exchanges, and an improving employment market.

Between 2008 and 2014 (the most recent data), rates of children's coverage grew nearly 4 percentage points; to 94 percent. Growth in public insurance, such as Medicaid and the Children's Health Insurance Program (CHIP), was largely responsible for these gains (up 10.8 percentage points since 2008), while rates of private insurance coverage fell concurrently (down 5.6 percentage points). But between 2013 and 2014, the combined rise in public coverage ( 0.8 percentage points) and private coverage (0.4 percentage points) produced the second-largest overall gain-1.1 percentage points-in children's insurance rates in the seven-year span. The largest increase- 1.4 percentage points-occurred between 2008 and 2009 when Congress and the Obama Administration reauthorized CHIP.

Private insurance rates rose most in the rural Midwest and South as well as in Western cities in 2014, while public insurance grew most significantly in suburban places in the Northeast, South, and West.

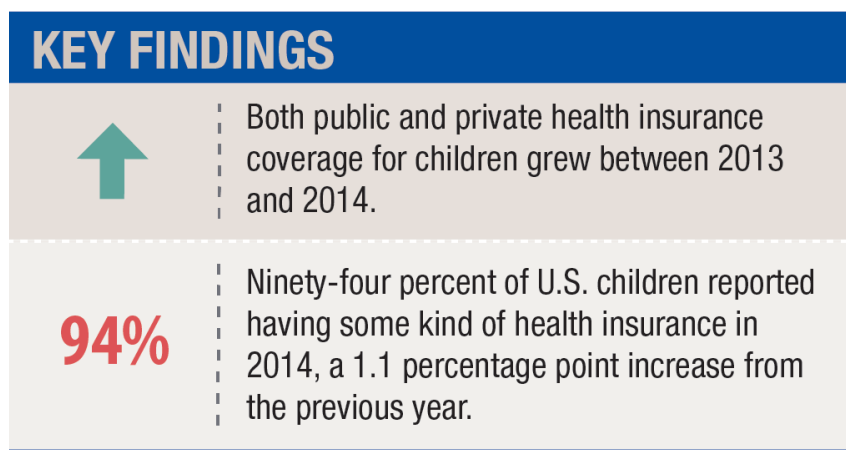

Medicaid expansion and outreach, also components of ACA, were already underway when the individual mandate took effect in 2014, and they largely explain growing rates of public coverage among children. As adults turned to insurance marketplaces to enroll in private coverage in response to the individual mandate, children also experienced an increase in private coverage alongside their adult counterparts. Federal subsidies and premium tax credits to low-income and qualifying individuals also took effect in 2014, and these may have encouraged families to enroll in private health plans.

Finally, a more robust employment market, including jobs that provide health coverage to employees and dependents, may have also bolstered rates of private insurance. 
FIGURE 1. RATES OF CHILDREN'S HEALTH INSURANCE IN THE UNITED STATES, OVERALL, PRIVATE, AND PUBLIC, 2008 TO 2014

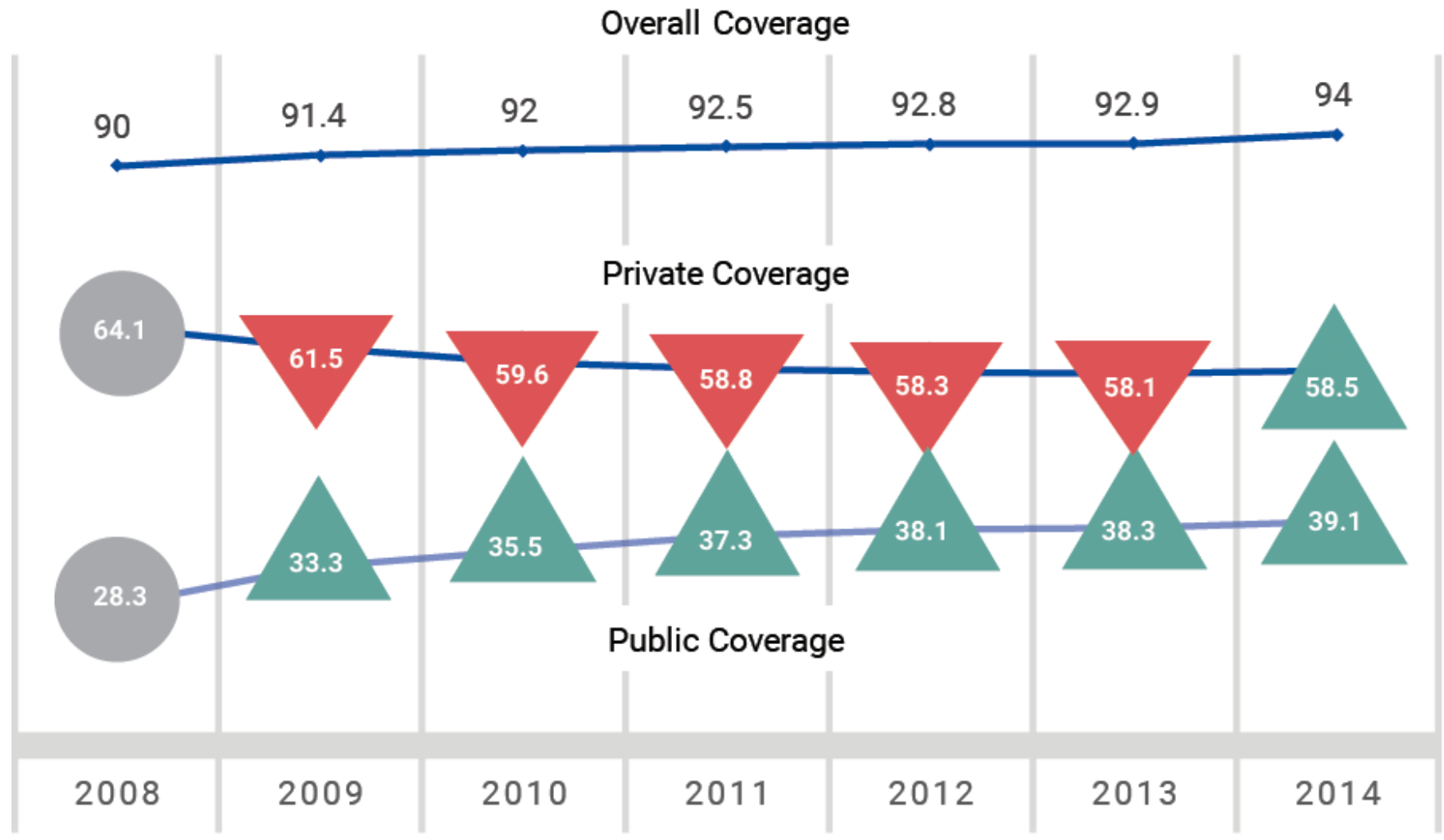

Note: Public and Private insurance percentages do not sum to the total number of insured; some children have both types of coverage. Source: American Community Survey 2008-2014

\section{Data}

This analysis is based on U.S. Census Bureau estimates from the American Community Survey for years 2008-2014. Tables were produced by aggregating information from detailed tables available at the Census Bureau's American FactFinder (http://factfinder2. census.gov). Because estimates are based on survey data, caution must be used when comparing data from different years, as the margin of error may indicate that seemingly disparate numbers fall within sampling error (see the Census Bureau's published tables for detailed margins of error, available at http://www.census.gov/ acs/www/Downloads/handbooks/ACSResearch.pdf). All differences highlighted in this brief are statistically significant $(p<0.05)$.

\section{A c k n o w l ed g me n t s}

The author is grateful to Jessica A. Carson for data analysis and to Jennifer Clayton for her assistance. Marybeth Mattingly, Michele Dillon, Amy Sterndale, and Michael Ettlinger provided valuable feedbackthank you. And many thanks to Laurel Lloyd for designing and formatting the layout of this publication and to Bianca Nicolosi for her aid in adapting the information for electronic formats.

\section{About the Author}

Michael J. Staley is a research assistant at the Carsey School of Public Policy and a doctoral candidate in the Department of Sociology at the University of New Hampshire (michael.staley@unh.edu). 